\title{
Fuzzy Inference System for Modelling Failure Modes in a Ropeway for Massive Transportation
}

\author{
Luisa F. Villa \\ Department of Mechanical Engineering \\ GEMI Research Group \\ Universidad EAFIT \\ Carrera $49 \mathrm{~N}^{\circ} 7$ Sur - 50, Medellin, Colombia \\ O.L. Quintero Montoya \\ Department of Basic Sciences \\ Mathematical Modeling Research Group \\ Universidad EAFIT \\ Carrera 49 N $^{\circ} 7$ Sur - 50, Medellin, Colombia
}

\author{
L. Castañeda \\ Department of Mechanical Engineering \\ GEMI Research Group \\ Universidad EAFIT \\ Carrera $49 \mathrm{~N}^{\circ} 7$ Sur - 50, Medellin, Colombia \\ G. Mejía \\ Metro de Medellín Ltda. Calle 44 46-001, \\ Bello, Antioquia, Colombia
}

\begin{abstract}
This work uses Fuzzy Inference Systems to model the failure modes of the Metrocable (ropeway massive transportation system in Medellín-Colombia) and to this aim, handle the concept of Condition Based Maintenance (CBM) for the automation of maintenance routine. Maintenance procedures in this massive transportation ropeway system have been designed from manufacturer and improved by expert knowledge trough years of operation, so they can be modeled by fuzzy models. The following work is part of the project "Diagnostic system of the interface grip-cable of the Metrocable", developed between the entities COLCIENCIAS, Metro de Medellin and Universidad EAFIT.
\end{abstract}

Keywords-fuzzy inference systems; ropeway; massive transportation systems; condition based maintenance

\section{INTRODUCTION}

The Metrocable System is the first massive transportation ropeway in the world and operates around 19 hours per day. The maintenance requirements of the system are higher than others ropeways and it is extremely necessary verify the conditions of operability, maintainability and safety of the users and the system itself. To increase the system availability, is important have an efficient maintenance tasks grouped in a good maintenance strategy. Good maintenance is achieved by having few corrective maintenance tasks and reducing the preventive maintenance to minimums. Condition based maintenance is one possible way of achieving this. Maintenance tasks are developed following the manufacturer instructions, but due to the nature of the system operation, engineers have developed other tasks associated with the new dynamics of the ropeway operation. New maintenance routines have been established and expert knowledge accumulated trough time. Expert knowledge about this system is basically found in the so called "failure modes" defined by maintenance personnel; relating the measured variables of the cabin and station with the possible failures of parts and components of the system. The situations described by failure modes can occur during operation of the system and can be caused by external phenomena like wind and weather conditions, or mechanical damages like wear. The use of condition based maintenance ensures that the condition of an element is always monitored and alarm limits can be programmed or specified to alert attention if the condition exceeds specified accepted levels. Indepth analysis of the monitored data provides a diagnosis and prognosis of an incipient fault. Everything is taken into consideration when scheduling predictive maintenance actions, autonomously or in interaction with humans. Investigations indicate that there is a lot of money to gain in increasing item availability, with the implementation of condition based maintenance as one possibility [2].Fuzzy Inference Systems (FIS) modeling of failure modes will be included into a SCADA Expert system that contains a specific phase of instrumentation of the interface grip-cable (the real time acquisition of some measurements related to the station and the cabin); the measurements will be the inputs to the FIS for failure modes.

This work will focus on the modeling of the human knowledge to estimate the behavior of the system in terms of Condition Based Maintenance. The OSA-CBM (Open System Architecture - Condition Based Maintenance) requirements of the architecture for CMD (Condition Monitoring Diagnosis) were designed in accordance with the ISO 13374-1:2003 (E) [3] and ISO 13374-2:2007 (E) [4].

This paper is organized as follows: section 2 presents the Metrocable system description, condition based maintenance definitions and theory of the Fuzzy Inference systems, section 3 presents the failure modes modeled to improve the condition based maintenance tasks in Metrocable, finally section 4 shows the results and conclusions.

\section{MATERIAL AND METHODS}

\section{A. Metrocable system description}

Metrocable system operates under the modality of ropeway of continuous cycle, uncouple single cable. This means that uses a single cable that serves as carrier and tractor cable. As the cable is in continuous movement, the system disengages and engages the cabin to the entry and exit of each station respectively [5]. The cabins have a unidirectional or circulating 
movement; the movement direction not changes, at least in normal conditions. The route of the cabin is performed at constant speed, once it enters to the station, the cabin uncoupling of the cable and coupling in the station slowing gradually to be boarded by the passengers. The union of the cabin with the cable is temporary, meaning that the cabin joins to the cable once it leaves the station and that is uncoupling of the cable when it enters to the next station. The connection between the cabin and the cable is performed through a detachable grip [6]. The description of each of these two components presented below.

1) The grip: The grip is an assembly composed of several elements that act together to allow the cabin coupling and uncoupling completely from the cable during his route for the station. The grip uncoupling when enters the station and this requires the interaction with the three tracks that make the station: the stabilization rail, the circulation rail and the coupling and uncoupling rail. The coupling function is performed when leave the station, and for this should also contact with the three rails mentioned above [7].

2) The station: The station is composed by three rails: the stabilization rail, the circulation rail and the coupling and uncoupling rail. It also has a drive system consists of tires. This is supported by supporting beams and columns type swan neck[8].

3) Fuzzy systems: In artificial intelligence, fuzzy logic is useful tool to solve a variety of problems related with control of industrial processes and decision systems. The Fuzzy logic is an extension of classic logic that uses the concepts of membership to sets in a way that is more similar to human thinking. It is also a multivalued logic, that allows intermediate values to be defined between conventional evaluations, where a membership function assigns to each object a grade of membership to a set ranging between zero and one [1]. A key characteristic of the fuzzy logic is that it enables to emulate human reasoning mechanism, which ability to model nonlinear problems, flexibility and tolerance for inaccuracy. The fuzzy set theory is the basis for the formulation of the variables categorization that related by "if-then" rules constitute the core of the Fuzzy Inference System (FIS). The FIS consists of three conceptual aspects: a rule base, a database and a reasoning mechanism. The rule base covers the selection of fuzzy rules are constructed according to the input variables of the system in relation to its effect on the output variable, the database, defines the membership functions created by the Fuzzification process that allows the user to convert a numerical variable value to a fuzzy number that represents the degree of membership of the variable to a category or set. The membership functions make each input variable and output by categorization and are the categories used for the construction of the rules, and finally the mechanism of reasoning is the process of inference rules through a defuzzification method to find the estimated variable output [9, 10].Based in the Mamdani fuzzy inference system, the methodology of this work can be summarized in the following procedure [10]:1)
Understand the problem as a dynamic system.2) Extraction, organization and analysis of data.3) Categorized the variables, inputs and outputs.4) Definition of the fuzzy sets.5) Creation of the rule base based on system operating characteristics, expertise and combinations of the input variables. 6) Model validation.

\section{B. Condition based maintenance systems}

Various researchers have defined condition based maintenance [11, 12, 13]. For this work, condition based maintenance has been defined as [14]: "Preventive maintenance based on performance and/or parameter monitoring and the subsequent actions." Condition based maintenance is thus a maintenance technology that utilizes condition monitoring tools to analyze the current condition of the element and, through that knowledge, set up proper preventive maintenance schedules. Since the maintenance intervals and tasks are based on the condition of the element, they are predictive. Predictive maintenance has been defined as: "Condition based maintenance carried out following a forecast derived from the analysis and evaluation of significant parameters of the degradation of the element.” [14][15, 16].In this work, the idea of a condition based maintenance system is defined as: "A system that uses condition based maintenance to determine and schedule predictive maintenance actions autonomously or in interaction with other systems or humans." Using [17] purpose of a technical system, one can say that the purpose of a condition based maintenance system is to transform certain well-defined input quantities in the form of energy (e.g. vibration, temperature etc.) into desired effects (e.g. information of the condition of the element, a prognosis on the future condition, etc.) in space and time. Condition based maintenance system will be developed, using FIS to relate the real time measured variables of the Metrocable system with the failure modes predefined by the experts. The FIS model will be used in a supervisory SCADA system for decision making. It is important to remark the fact that the failure modes are extracted by experience of operation through time and cannot be obtained directly from data. There are a combination of several variables behavior and external disturbances measured by real time measuring system.

Following this ideas, the SCADA expert system has as inputs the values of the measured variables and the configuration criteria of the system from previous analysis of historical data. The 18 variables measured in the SPD-CABLE system are delivered to the SCADA expert system duly acquired and manipulated physically and electronically fulfill layers 1 and 2 of the standard (ISO 13374-2:2007 (E) [4]). That is, the SCADA system inputs are digitalized signals in the LabVIEW platform that will be used for the other layers of the same standard and additional functions designed for the system. $[18,19,20,21,22,23,24]$.

The criteria for setting alarms and trend analysis of the mechanical conditions associated with the SPD-CABLE variables come from a quantitative and qualitative analysis of the historical maintenance of the Metro Company duly processed and analyzed by an expert in mechanical maintenance. 
That said, the SCADA expert system should comply with the other functions specified in the standard.

\section{FUZZY MODELING OF THE FAILURE MODES TO IMPROVE THE CONDITION BASED MAINTENANCE TASKS}

Failure analysis is the determination of failure modes of machinery components and their most probable causes. Failure mode (FM) is the appearance, manner, or form in which a machinery component or unit failure manifests itself. The meaningful classification of failure causes are: design deficiencies, material defects, processing and manufacturing deficiencies, assembly errors, off-design or unintended service conditions, maintenance deficiencies (neglect, procedures), improper operation. The failure causes are usually determined by relating them to one or more specific failure mode. The machinery failure mode classifications are: deformation, fracture, surface changes (wear), material changes, displacement, leakage, contamination [25, 26].Failure modes of Metrocable have been studied by the engineering team for years, so the failure modes associated with the input and transit of the cabin trough the station are associated with the components of the system as presented below in table 1 . Of this association are obtained 27 FIS, one for each failure mode.

TABLE I. RELATIONSHIP BETWEEN FAILURE MODES AND SYSTEM ELEMENTS

\begin{tabular}{|l|c|c|c|c|c|c|c|}
\hline $\begin{array}{c}\text { System } \\
\text { elements } \\
\text { Failure mode }\end{array}$ & Wheels & Clamps & Shaft & Ways & Belts & Cable & Tires \\
\hline Deformation & $\mathrm{X}$ & & & $\mathrm{X}$ & & & \\
\hline Fracture & & & $\mathrm{X}$ & & & & \\
\hline $\begin{array}{l}\text { Surface } \\
\text { changes (wear) }\end{array}$ & $\mathrm{X}$ & $\mathrm{X}$ & $\mathrm{X}$ & & $\mathrm{X}$ & & $\mathrm{X}$ \\
\hline $\begin{array}{l}\text { Material } \\
\text { changes }\end{array}$ & $\mathrm{X}$ & & $\mathrm{X}$ & & & & \\
\hline Displacement & & $\mathrm{X}$ & & $\mathrm{X}$ & $\mathrm{X}$ & $\mathrm{X}$ & \\
\hline Leakage & & & & & & & $\mathrm{X}$ \\
\hline Contamination & & & & $\mathrm{X}$ & & & \\
\hline
\end{tabular}

\section{A. System inputs}

From the knowledge of the maintenance routines that define the components and variables that require greater monitoring in the interface grip-cabin and grip-station are determined the variables to be monitored. Some of the characteristics that are verified in the maintenance routines that guarantee the security and integrity of the transportation system are the verifying of the geometric dimensions that monitor the correct location of the cable, the contact of the grip with the different ways of the station and the possible fluctuations in the cabin at entrance or exit of the station and the impacts these may produce in the fixed parts of the station.In the SPD-CABLE 18 variablesare measured to define the operation, availability and maintainability of the system, these variables belong to subsystems located in the clamp and the station. These variables represent geometric dimensions that are both linear and angular, forces, vibration and pressure, among others. The variables control the operating status of the equipment, when a variable goes out of its range is due to a malfunction. A failure mode is defined by different causes (variables) that when they occur at the same time generates that failure and thus has an effect on the system.

\section{B. Inference engine of the expert system}

In the case of the SCADA expert system development for the Metrocable system, a fuzzy model was generated for each failure mode of the system following the methodology cited in section 2.2. These failure modes come from the relationship of the variables monitored with the elements of the system and the different faults that can occur in each element. The relations cause-effect over all the input variables and failure modes was made thinking about the engineering analysis and the expert knowledge of the operators. Each failure mode is modeled through a FIS associated to a number from 1-27. Some failure modes FIS models not only have the measured variables as inputs, but also have other failure modes as causes, some FIS models feed the FIS models to some other failure modes.

Building each failure mode as a FIS by the use of expert knowledge, can be determined not only whether a variable is out of range, but also find the effect of that variable on the overall operation of the equipment. The membership functions of the inputs for the FIS in each failure mode are created having into a count the range established by the manufacturer, the expertise gained through the time by the experts in maintenance and the tendencies and distribution of the historic stored during the maintenance task. The rule base is constructed from expert knowledge, for it is given priority in these rules to the variables (causes) more critical for the failure mode being analyzed. The probability of occurrence of the failure mode is greater when altered the values of the variables most critical to this failure mode.

\section{Decision making and diagnosis model}

To define the structure of decision making in the system, was used the general approach to the choice of a diagnostic model that present the norm ISO 13379-1:2012 (E) [27]. Evidently the problem to solve in this case does not involve only one of the methodologies cited for this purpose, because data and knowledge are available. Several previous analyses of the phenomena were performed to extract causal relationships, first principles equations; rule based reasoning and real data. Interviews with expert maintenance personnel were developed and experimentally tested the failure modes to be monitored and the knowledge based new rules.

The way of deliver to maintenance personnel the outputs of the SCADA system so that they can know the status of the system and to carry out appropriate maintenance is through a maintenance work order optimized. The maintenance data obtained from performing these maintenance tasks, will serve as feedback system inference.

\section{CONCLUSIONS}

We demonstrate that fuzzy logic can be used to the building of failure mode models for a Metro Cable System in Metro de Medellin - a first ropeway massive transportation system in the world. The importance of this methodology relays in the fact that we use a scheme for Condition Based Maintenance Systems (CBMS) following the standard ISO 13374-2:2007 and the fuzzy logic models are part of a SCADA expert system. CBMS's are based in real time monitoring of variables to determine the status of the variable into the system, trying to relate these variables into sub systems that explains causes and 
effects. By grouping them into a fuzzy logic models, we can get full advantage of the experience of the human experts in maintenance during maintenance practices. In addition, the prediction capabilities of the model feed the SCADA system looking for real time reporting. Into the SCADA, the information can be easily used by the users and through a "maintenance order", optimizing the programming of the maintenance tasks minimizing costs and preventing damages of the system.

\section{REFERENCES}

[1] L. A. Zadeh, Fuzzy sets, Information and control, 8,338-353, 1965.

[2] M. Bengtsson, Condition based maintenance systems - an investigation of technical constituents and organizational aspects, Department of Innovation, Design, and Product Development, Mälardalen University, 2004.

[3] International Standard ISO (ISO 13374-1:2003 (E)), Condition monitoring and diagnostics of machines - Data processing, communication and presentation - Part 1: General guidelines

[4] International Standard ISO (ISO 13374-2:2007 (E)), Condition monitoring and diagnostics of machines - Data processing, communication and presentation - Part 2: Data processing.

[5] A. Orro, M. Novales, M. Rodriguez, Transporte por cable. Ed. Tórculo Artes Gráficas, A Coruña. 2003.

[6] M. O. Löhr, Simulation der StationseinfahrtkuppelbarerEinseilumlaufbahnen, LehrstuhlfürFördertechnikMaterialflussLogistik der TechnischenUniversitätMünchen, München, Deutschland. 2002.

[7] Pinzas desembragables oméga T y oméga TL, Reseña técnica PIN 001, POMA. Pomagalski S.A.

[8] Vías de desembrague-embrague de las pinzas, Reseña técnica VOI 001, POMA. Pomagalski S.A.

[9] P. Ponce, Inteligencia artificial con aplicaciones a la ingeniería, Alfaomega Grupo Editor, Pag. 348. S.A DE C.V., 2010.

[10] J. R. Jang, C. Sun, E. Mizutani, Neuro-Fuzzy and soft computing. A computational approach to learning and machine intelligence.Prentice Hall. 1997.

[11] J. S. Mitchell, (1998). Five to ten year vision for CBM, ATP Fall Meeting - Condition Based Maintenance Workshop.USA, Atlanta, GA, 1998 (PowerPoint Presentation), http://www.atp.nist.gov/files/3 (200310-08).

[12] S. W. Butcher, Assessment of condition - based maintenance in the department of defense, Logistics management institute, McLean, Virginia, USA. 2000.

[13] C. C. Moya, and J. C. H. Vera, Evaluation of Condition Based Maintenance through Activity Based Cost, Maintenance Journal. Vol. 16, No. 3, pp. 54-61, 2003.

[14] Maintenance terminology, Swedish standard institute, (SS-EN 13306, 2001)

[15] A. G. Starr, A structured approach to the selection of condition based maintenance, 5th International IEE Factory 2000 Conference, Cambridge, 1997.

[16] B. Al-Najjar, and I. Alsyouf, Selecting the most efficient maintenance approach using fuzzy multiple criteria decision making, International journal of production economics. Vol. 84, Issue 1, pp. 85-100, 2003.

[17] V. Hubka, Principles of engineering design, Butterworh scientific, England, 1982.

[18] G. Johannsen, Knowledge based design of human machine interfaces, Control Eng. Practice, Vol. 3, No. 2, pp. 267-273. 1995.

[19] T. L. Optin, Intelligent SCADA systems, Automation \& Control Technical, EngineerIT, April 2007.

[20] Z. Aydogmus, Implementation of a fuzzy-based level control using SCADA, Expert Systems with Applications, 36 (2009) 6593-6597.

[21] J. Alfredson, J. Holmberg, R. Andersson, M. Wikforss, Applied Cognitive Ergonomics Design Principlesfor Fighter Aircraft, D. Harris
(Ed.): Engin. Psychol. and Cog.Ergonomics, HCII 2011, LNAI 6781, pp. 473-483, 2011.

[22] G. Yang, J. Niu, F. Wang, S. Cui, L. Zhao, Multi-mode Human-Machine Interface for Robot, Y. Wu (Ed.): Advances in Computer, Communication, Control \& Automation, LNEE 121, pp. 205-212, 2011.

[23] J. S. Kong, K. Maute, D. M. Frangopol, L. A. Liew, R. A. Saravanan, R. Raj, A real time human-machine interface for an ultrahigh temperature MEMS sensor-igniter, Sensors and Actuators A, 105 (2003) 23-30.

[24] K. Ravaie, A. Haji-Valizadehb, Selecting human machine interface package in integrating a process automation system, ISA Transactions 41 (2002) 115-126.

[25] H. P. Bloch and F. K. Geitner, Practical machinery management for process plants, Volume 2: Machinery failure analysis and troubleshooting. Gulf Publishing Company, Houston, Texas, United States of America, 1983.

[26] R. A. Collacott, Mechanical fault diagnosis and condition monitoring. Chapman and hall, London, United Kindon, 1977.

[27] International Standard ISO (ISO 13379-1:2012 (E)), Condition monitoring and diagnostics of machines - Data interpretation and diagnostics techniques - Part 1: General guidelines. 